\title{
ETCHPLANAÇÃO DINÂMICA E EPISÓDICA NOS TRÓPICOS QUENTES E ÚMIDOS
}

\author{
Antonio Carlos Vitte ${ }^{1}$
}

Resumo: 0 artigo apresenta a teoria da etchplanação como um referencial teórico e metodológico para os estudos das formas de relevo nas regiões tropicais quentes e úmidas, destacando o papel do intemperismo químico e dos sistemas de transformação da cobertura pedológica. A originalidade da teoria da etchplanação é que ela considera os processos geoquímicos e pedogenéticos como os principais mecanismos da morfogênese e do aplainamento das formas de relevo. Neste trabalho são discutidos a gênese da teoria da etchplanação, o intemperismo químico como mecanismo básico do aplainamento das formas de relevo e uma proposta de trabalho com a etchplanação.

Palavras-chave: Regiões tropicais quentes e úmidas; Etchplanação; Intemperismo químico; Cobertura pedológica; Bacias de drenagem.

\section{Introdução}

Atualmente, na pesquisa geomorfológica, com 0 desenvolvimento do paradigma (KHUN, 1986) da etchplanação, questiona-se o papel do intemperismo no desenvolvimento do relevo (BATTIAU-QUENEY, 1996). Nas teorias de DAVIS (1899) e de KING (1953), as variáveis estrutura e clima, sob fundamentação cíclica, condicionaram as análises, enquanto que 0 papel das alterações geoquímicas das rochas foi negligenciado, particularmente pela Teoria da Pediplanação.

0 objetivo do presente trabalho é realizar um resgate sobre a Teoria da Etchplanação Dinâmica para as Regiões Tropicais Quentes e Úmidas, apontando a necessidade de uma abordagem mais analítica do perfil de intemperismo e dos sistemas de transformação da cobertura pedológica nas análises geomorfológicas. 0 trabalho também procura chamar a atenção para a necessidade de uma abordagem escalar quando se considera a etchplanação. Nela, a bacia hidrográfica, que é a unidade natural de trabalho em geomorfologia, funciona como nível escalar básico, permitindo a compreensão do porquê das variações espaço-temporais dos processos morfogênicos dinamizados pela etchplanação. 0 sistema fluvial em seu funcionamento sistêmico, associado às propriedades geomorfológicas do canal fluvial, às características lito-estruturais e a história paleoclimática, pode dinamizar 0 aprofundamento do front de alteração e o conseqüente aplainamento do relevo de uma determinada área de maneira diferencial, resultando em uma variedade de formas associadas a um mesmo processo e sistema de alteração geoquímico.

\section{Breve história da geomorfologia tropical}

A idéia de que um tipo climático específico é capaz de produzir um determinado compartimento de relevo foi desenvolvido por William M. Davis em 1899 e incorporado por COTTON em 1942 (apudFANIRAN e JEJE, 1983:3).

Para WIRTHMANN (1999) a história da geomorfologia tropical inicia-se com os trabalhos de Alexander VON HUMBOLDT (1769-1859) que coletou importantes evidências geomorfológicas dos trópicos, particularmente pela observação do rio Orinoco e de drenagens no México.

Mas, para CHORLEY et al. (1984), foram com os trabalhos de Dana, geólogo norte-americano que estudou algumas ilhas do Pacífico e rios da Austrália, que iniciaram as preocupações com a moderna geomorfologia tropical. Dana registrou as relações entre as tipologias de vale fluvial e a distribuição da vegetação neles; reconheceu o papel do escoamento linear no modelamento das encostas; a erosão dos talvegues e, finalmente, a relação entre a decomposição geoquímica das rochas e as superfícies aplainadas.

PASSARGE (1895) e BORNHARDT (1900) também contribuíram para 0 desenvolvimento da geomorfologia tropical na medida em que noticiaram a existência de extensos etchplains e inselbegs nos escudos tropicais. Uma imensa sucessão de inselbergs na savana africana, nos desertos e nas regiões florestadas de outros continentes localizados na região tropical foi descrita. Esta forma de relevo propiciou um intenso debate, além de ser foco de interesse por parte dos geomorfólogos e naturalistas.

Outro debate importante suscitado pelas descobertas no mundo tropical e que impulsionou a geomorfologia tropical foi 0 relativo aos materiais que circundam os inselbergs. Estes seriam

1 Departamento de Geografia, UNICAMP, CP 6152, Campinas (SP), CEP 13087-970. e-mail: vitte@uol.com.br. Pesquisador CNPq 
produto de um rolamento provocado pelas águas superficiais ou produto da dissecação fluvial da paisagem? Qual seria o papel do clima, dos paleoclimas e da história geotectônica na constituição dos inselbergs? (PASSARGE, 1904a, b, c, 1924, 1929; BORNHARDT, 1900).

Assim, a partir da descoberta dos Inselbergs no mundo tropical, imediatamente as atenções voltaram-se para 0 seu contexto regional, no caso, as associações entre os Inselbergs e as extensas superfícies planas. A nova obsessão passou a ser a busca de explicações para a existência das superfícies de aplainamento.

0 primeiro modelo de aplainamento tropical, desenvolvido por Jessen, em 1936, admitiu que toda a superfície da Terra havia sido aplainada durante 0 Terciário quando havia um tipo climático úmido e sazonal similar ao atual. No transcorrer do Terciário, 0 clima sofreu mudanças, com a geração de vales muito entalhados, similares aos encontrados nas zonas periglaciais.

As pesquisas associadas ao maior conhecimento da dinâmica climática da região tropical foram desenvolvidas com base em duas frentes de interpretação da dinâmica das paisagens no mundo tropical. Vale frisar que estas duas frentes sofreram problemas de interconexão entre elas, pois para as áreas tropicais onde domina a sazonalidade climática foram associadas a formação de inselbergs e aplainamentos, enquanto que nas áreas tropicais onde a umidade é constante, os estudos preocuparam-se com a formação e desenvolvimento das vertentes. Criando assim, problemas para a interpretação holística sobre a história e a evolução do relevo na região tropical.

\section{A complexidade na delimitação da região morfoclimática}

Segundo FANIRAN e JEJE (op.cit.), a geomorfologia climática postula que diferentes climas podem produzir diferentes processos e compartimentos de relevo a ele associados, formando assim, as regiões morfoclimáticas. No entanto, PASSARGE (1926) chamou a atenção para a necessidade de se considerar as interferências paleoclimáticas na geração das atuais formas de relevo.

Os trabalhos de BÜDEL $(1950,1957,1980,1982)$ e BREMER $(1971,1981,1992,1993)$ passaram a considerar a concepção climatogenética do relevo, na qual o desenvolvimento do relevo obedece a estágios de evolução geomorfológica. Essa evolução geomorfológica é derivada de diferentes situações paleoclimáticas e estruturais e não apenas produto do clima atual.

Dentre as possibilidades de cartografação das regiões morfogenéticas, PELTIER (1950), por exemplo, utilizou como critério para definir uma região morfoclimática a precipitação média anual e a temperatura que, segundo ele, tinham efeito sobre 0 intemperismo e os processos erosivos. Com esta classificação, foi possível estabelecer uma primeira distinção entre 0 morfoclima tropical dos demais tipos.

Para STODDART (1969), a classificação de PELTIER (1950), embora muito indutiva representou um primeiro passo para 0 mapeamento de regiões morfoclimáticas distintas. Mapeamento que, segundo STODDART (op.cit), deveria estar fundamentado em uma rigorosa análise da topografia, auxiliada por técnicas, como 0 uso de fotografias aéreas. Para STODDART (op.cit), a relação entre as formas de relevo e a vegetação seria o melhor critério para se definir uma zona morfoclimática.

DOUGLAS (1969), ao contrário, considera que 0 melhor critério para se definir uma zona morfológica seja o estabelecimento da relação entre a produção de sedimentos dos rios e 0 clima. No entanto, THOMAS (1994) ressalta o perigo deste critério, pois as bacias podem estar sob efeito da ação tectônica que pode alterar a magnitude da produção de sedimentos, além do que, se for considerada a atual situação de desmatamento no mundo, este pode ser mais um elemento complicador para as análises e para a cartografação de regiões morfoclimáticas.

Uma outra possibilidade de estabelecimento das regiões morfoclimáticas é o uso de parâmetros climáticos ou mesmo de classificações climáticas. Assim, a UNESCO (1978, apud THOMAS, 1994) classificou o trópico úmido como sendo a área do planeta que apresenta temperatura média acima de $20^{\circ} \mathrm{C}$ e precipitação média anual acima de $1000 \mathrm{~mm}$, que coincidiria com o tipo climático Af de Köppen. Este tipo de aproximação foi utilizado por FANIRAN e JEJE (1983) e TRICART (1972).

Segundo THOMAS (1994), um outro parâmetro possível de se utilizar no mapeamento das regiões morfoclimáticas é a relação entre a intensidade da precipitação e a erosão. No entanto, 0 problema para 0 uso deste parâmetro é o fato de que a região tropical apresenta uma dinâmica atmosférica representada por uma variedade de eventos, como depressões, furacões, monções e sistemas frontais controladores dos tipos de tempo, que podem interferir na temporalidade das precipitações e com isto mascarar diferenças importantes na própria zona tropical.

Conforme já foi colocado, o problema da geomorfologia climática é definir quais critérios devem ser utilizados para delimitar e estabelecer as relações entre uma determinada região climática e as formas de relevo.

Neste trabalho defende-se que a maneira mais adequada de se trabalhar com a geomorfologia tropical seja utilizar como critério 
a associação entre a forma do relevo, com a profundidade do intemperismo e com os minerais de argila predominantes no solo, conforme foi descrito por STRAKOHOV (1963). MILLOT (1983) foi um dos autores que reconheceu os diferentes estilos de paisagens desenvolvidas sob mantos cauliníticos, lateritas, esmectitas e relevos em calcário.

Uma outra alternativa é considerar mais detalhadamente a importância do intemperismo químico e da pedogênese, além da tectônica e dos paleoclimas na morfogênese tropical, a forma como foi desenvolvida na geomorfologia climatogenética que está relacionada à concepção de etchplanação.

\section{A Teoria da Etchplanação.}

0 papel do intemperismo na dinâmica morfológica das paisagens passou a receber atenção a partir da Teoria da Etchplanação, desenvolvida inicialmente por WAYLAND (1933), quando trabalhou em Uganda. Para ele, as pene-planícies de Uganda são formadas pela alternância entre a alteração geoquímica das rochas e a erosão superficial, enfatizando que 0 processo de Etchplain é marcado com uma paisagem profundamente alterada, que posteriormente sofreu a ação de um ciclo erosivo com a exposição do saprolito, formando uma planície rochosa. 0 saprolito apresenta topo-grafia irregular estando sujeito a um novo ciclo de alteração e erosão, de maneira que as suas irregularidades são paulatinamente expostas à superfície, criando inselbergs na paisagem (OLLIER, 1975).

A Teoria da Etchplanação foi revolucionada com os trabalhos de BÜDEL $(1957,1963,1982)$ que, com o conceito de Dupla Superfície de Planação, consolidou o papel do intemperismo na análise geomorfológica (THOMAS, 1989, 1989a). Sua concepção é de que existe uma integração dialética entre a alteração geoquímica das rochas e a erosão superficial (BÜDEL, 1982). Os processos de lixiviação e lessivagem promovem a disjunção nas ligações ferro-argila instabilizando os horizontes superficiais e preparando-os para o processo erosivo nas encostas. A migração das argilas, oxihidróxidos de ferro e alumínio e ácidos orgânicos em profundidade intensificariam o aprofundamento do intemperismo.

Assim, a formação do relevo ocorre pela interação entre a superfície topográfica e uma subsuperficial existente no contato entre a rocha e a zona de alteração, que, para BÜDEL (1957), é paralela à superfície, sendo designada por BERRY e RUXTON (1957) de superfície basal de intemperismo.

No entanto, OLLIER (1969) enfatizou que o aprofundamento da alteração é mais irregular que propriamente paralelo à superfície. 0 saprolito pode ser profundamente alterado em algumas zonas, enquanto que em outras zonas a alteração não é substancial. Tal constatação levou MABBUT (1962) a alterar 0 termo superfície basal de intemperismo para front de alteração.

Para BÜDEL (1957, 1963), a formação dos etchplains está associada, particularmente, aos trópicos sazonais (com 6-9 meses de precipitação) e às áreas tectônicamente estáveis, cujo modelo empírico foi a planície de Tamilnad, no sudoeste da Índia.

No entanto, BÜDEL (1982) passou a admitir a existência de etchplains nos trópicos úmidos e em seu processo, além da alteração das rochas participam também as variações climáticas. Este autor considera quatro circunstâncias necessárias para a existência da etchplanação:

- a existência de latossolos;

- um perfil homogêneo, indicando que o solo possui evolução dinâmica;

- uma transição delgada entre a rocha e 0 material alterado, particularmente em rochas fraturadas, onde 0 intemperismo é intenso e;

- uma zona de decomposição rochosa profunda e generalizada, entre 100 e $150 \mathrm{~m}$ de espessura.

A formação do relevo iniciar-se-ia com 0 abaixamento gradual da superfície, sendo que a intensidade do abaixamento é resultante do aprofundamento da topografia do front de alteração (BÜDEL, 1977, 1982). Por causa das irregularidades do front de alteração que, segundo TWIDALE e LAGET (1993), são provocadas pela existência de falhas, fraturas e arranjo das estruturas, a superfície basal de intemperismo pode apresentar corcovas, enquanto que em outras situações, em função da existência de juntas, porções rochosas do front de alteração são desprendidas e formam blocos rochosos que se distribuem sobre esse front de alteração.

Os horizontes superficiais, por sua vez, ficam predispostos à erosão mecânica, por causa das influências sazonais da atmosfera, da ação biológica da fauna endopedônica e dos ácidos orgânicos. Estes mecanismos levam à aluição do fundo matricial por meio da quebra nas ligações ferro-argila, promovendo gradativamente a liberação de finos e solutos pela ação do escoamento superficial pluvial. Esta ação resulta no abaixamento da paisagem, ao mesmo tempo em que o lençol freático é enriquecido com cátions e íons que passam a circular no topo do front de alteração viabilizando a destruição da rocha.

Nas zonas em que a alteração é profunda ou onde ocorre latossolo surgem depressões e o aprofundamento é dependente da intensidade do intemperismo e da ação do lençol freático. 0 lençol freático por sua vez, confina-se em falhas e fraturas, bem 
como pela diferença de alterabilidade das rochas. Assim, falhas e fraturas e a alterabilidade das rochas condicionam a velocidade da alteração ao mesmo tempo em que isolam zonas com graus diferentes de alteração (BÜDEL, 1982; TWIDALE e VIDALROMANI, 1994).

Estas depressões têm a função de receber e canalizar 0 escoamento superficial e subsuperficial, além de acumular sedimentos. Por outro lado, na medida em que canalizam as águas de infiltração para 0 front de alteração, mantêm a recarga na estação seca (BREMER, 1977).

Com o progressivo aprofundamento diferencial do front de alteração, associado à erosão superficial, os setores da superfície basal de intemperismo que não sofreram alteração gradativamente vão sendo alçados à superfície, originando inselbergs.

BREMER $(1971,1977)$ introduziu o termo intemperismo divergente para explicar as variações morfológicas da paisagem. $\mathrm{Na}$ etchplanação de BÜDEL (1982), o desenvol-vimento do relevo dar-se-ia em substrato homogêneo. Mas, as características do substrato, associado às pro-priedades geoquímicas das rochas (TWIDALE, 1983; KROONENBERG e MELITZ, 1983), induzem ao aumento de intensidade do intemperismo químico, viabilizando a ação morfogenética por meio dos processos fluviais e movimentos de massa. Esses movimentos de massa promovem 0 abaixamento do relevo em rochas pouco competentes e, nas mais resistentes são desenvolvidos inselbergs.

MILLOT $(1980,1983)$ introduziu o termo Planação Climática que, segundo THOMAS (1989a), representa uma variação francesa da teoria da etchplanação desenvolvida por BÜDEL (1957;1982). Na planação climática dá-se destaque para o papel da cobertura pedológica no desenvolvimento das formas de relevo, dado o fato que a abordagem na etchplanação sobre os solos e 0 intemperismo é muito genérica e porque os mecanismos pedogenéticos não foram destacados na teoria da Etchplanação desenvolvida por BÜDEL (1982).

Na interpretação de Georges MILLOT (1983), o intemperismo e a pedogênese são fatores muito ativos e intermediários entre 0 embasamento e a erosão superficial. 0 papel do intemperismo é 0 da desagregação, com transformação isovolumétrica da rocha, sem afetar as características e propriedades do relevo. A pedogênese, por sua vez, pelos mecanismos de dissolução, hidrólise e lixiviação, que são muito ativos próximos à superfície, promove a transformação dos produtos da alteração. A pedogênese é 0 "motor" dos fenômenos de aplainamento em zonas de desequilíbrio pedobioclimático, por meio da separação entre o plasma e 0 esqueleto, no interior da cobertura pedológica, preparando os horizontes superficiais à ação da erosão superficial (BOULET, 1974; BOULET et al., 1977).

Ainda para MILLOT (1983), a Planação Climática em clima tropical com regime sazonal ocorre pela discordância entre 0 front de alteração e 0 sistema pedológico. 0 front de alteração marca a discordância entre 0 saprolito e a rocha e sua característica é de transformação isovolumétrica. 0 sistema pedológico pode apresentar vários fronts (CHAUVEL e LUCAS, 1992; NAHON, 1991) que correspondem ao limite inferior dos horizontes. É próprio do sistema pedológico promover a discordância entre a matriz argilosa e 0 esqueleto, preparando os materiais para 0 aplainamento.

0 conceito de etchplanação vem sendo aplicado para as áreas tropicais que apresentam sazonalidade, já que durante a estação chuvosa há 0 aprofundamento da alteração, enquanto que a erosão superficial ocorre com maior intensidade durante a estação seca, promovendo a planação e, em alguns casos, expondo o front de alteração.

No entanto, para THOMAS (1994), a etchplanação também pode ser aplicada em região tropical úmida, onde adquire um caráter dinâmico, com intensa e profunda alteração, gerando uma superfície rochosa no front de alteração.

Um dos limites a ser destacado nos trabalhos de geomorfologia que utilizam o referencial da etchplanação é a não utilização da bacia hidrográfica como escala de referência de trabalho, o que é de grande utilidade para a compreensão do processo de etchplanação. A bacia hidrográfica e a situação geomorfológica do canal fluvial podem auxiliar na interpretação sobre a dinâmica intempérica-pedogenética e a conseqüente planação. A bacia hidrográfica é um geossistema que funciona pela constante troca de matéria e energia ao longo do tempo. Tal característica condiciona a estocagem, o volume e a velocidade da água do aqüifero ou mesmo do lençol subsuperficial da vertente, que exfiltram para 0 canal, determinando diretamente 0 tempo de residência da água no front de alteração ou no sistema pedogenético. A bacia hidrográfica determina, portanto, a velocidade das transformações geoquímicas no front de alteração, com conseqüência direta na velocidade de diferenciação e aplainamento do relevo.

0 grande problema em trabalhar com a etchplanação é estabelecer as relações entre 0 intemperismo e a planação (THOMAS, 1974, 1994; THOMAS e SUMMERFIELD, 1986). Para TWIDALE (1983) e THOMAS (1989), nas margens passivas, que correspondem a áreas cratônicas com relativa estabilidade geotectônica, a diferenciação do relevo nos últimos 100 milhões de 
anos foi proporcionada pela diferenciação das propriedades geoquímicas das rochas.

HACK (1960, apud THOMAS, 1994) acredita que a relação entre 0 intemperismo e a planação envolve a noção de equilíbrio entre a litologia e as condições climáticas. Esta relação, para FAIRBRIDGE e FINKEL (1980), é cíclica e ocorre seqüencialmente dentro do regime cratônico. Assim, em períodos de biostasia envolvendo 109 anos, ocorreria 0 aprofundamento e 0 espessamento do manto de intemperismo, caracterizando a etchplanação. Em curtos períodos (105 a 107 anos) de resistasia haveria, por sua vez, a formação de pediplanos e a exposição do front de alteração.

Um outro problema não resolvido pela teoria da etchplanação, segundo THOMAS (1994), é que os processos de erosão e sedimentação podem conduzir a mudanças nas características do perfil de intemperismo. A pedogênese em equilíbrio dinâmico promove a acumulação de óxidos e hidróxidos de ferro e alumínio, conduzindo ao desenvolvimento de couraças ferruginosas, que passam a influenciar na constituição do segundo tipo de etchplanação. Como feedback, a lixiviação e a lessivagem promovem 0 acúmulo relativo de esqueleto nos horizontes superficiais que, quando em fase resistática, serviram de base para a constituição de pedimentos e pediplanos.

BATTIAU-QUENEY (1996), BÜDEL (1982) e NOVIKOROFF (1943) afirmam que apesar da complexidade que envolve a pedogênese, ela pode ser considerada como parte do perfil de intemperismo. Para os primeiros autores, os horizontes superficiais do perfil correspondem a um reordena-mento espacial e mineralógico do saprolito fino, participando de tal processo os ácidos orgânicos e a biota do solo. Já para NOVIKOROFF (1943), mesmo em solos cumulativos, com complexidade estrutural e estratigráfica, 0 fenômeno está presente, seja pelos registros geoquímicos ou pela influência que 0 material poderá causar na velocidade de aprofundamento do front de alteração. Mesmo em situação de flutuação do lençol subsuperficial das vertentes, esta consideração deve ser feita, pois há a indução de movimentação de solutos e a neoformação mineralógica.

Assim, a cobertura pedológica e principalmente a noção de sistemas de transformação devem ser incorporados nos trabalhos de etchplanação dinâmica no mundo tropical, uma vez que as transformações geoquímicas e pedogeoquímicas podem acarretar a dinamização das formas de relevo.

\section{0 perfil de intemperismo e as margens cratônicas passivas}

0 intemperismo é a resposta das propriedades físicas, químicas e mineralógicas das rochas às condições existentes na superfície da Terra. 0 intemperismo resulta da interação entre a litosfera, a atmosfera, a hidrosfera e a biosfera (OLLIER, 1975; SUMMERFIELD, 1991; THOMAS, 1994).

Segundo TARDY (1969), os fatores que controlam o intemperismo químico são: a precipitação média, a quantidade de $\mathrm{CO}_{2}$ dissolvido na água de percolação na rocha, o tempo de residência da água em contato com os minerais e a temperatura ambiente do intemperismo (NAHON, 1991).

0 intemperismo químico distribui-se na crosta terrestre em consonância com os tipos climáticos (PEDRO, 1968), conduzindo a uma distribuição zonal de seu produto assim como de sua espessura, além de caracterizar os grandes tipos de alteração (PEDRO, 1966; PEDRO et al. 1975).

Na região tropical quente e úmida a alteração atinge todos os minerais primários simultaneamente. Esta alteração caracteriza-se por possuir grandes espessuras, chegando a constituir 0 solum e a alterita. A neoformação é o processo dominante na constituição dos minerais secundários. Na região tropical, a hidrólise é 0 principal mecanismo do intemperismo químico das rochas, podendo apresentar-se com graus diferenciados em função das condições termodinâmicas do meio (MELFI e PEDRO, 1977).

Caso a hidrólise seja total, os plagioclásios liberam SI, Al, $\mathrm{Na}$ e $K$ que aparecem no meio de alteração na forma de hidróxidos. A sílica e os cátions, em meio aberto, são liberados e o hidróxido de alumínio forma a gibsita. Com a hidrólise parcial, ocorre a sialitização que pode ser de duas formas: monossialitização, em que a dessilicificação é incompleta com a formação de caulinita. $\mathrm{E}$ na bissialitização ocorre a liberação parcial de cátions básicos com formação de montmorilonita.

MELFI e PEDRO (1977) e PEDRO e MELFI (1983) passaram a utilizar-se do conceito de grau de alteração, considerando a quantidade de minerais decompostos em relação ao total de minerais alteráveis na rocha original. Este conceito avança em relação ao tipo de alteração, na medida em que permite uma análise processual da alteração e de suas relações com 0 ambiente, permitindo acompanhar as transformações da alteração ao longo do tempo e suas conseqüências na paisagem, especialmente nas formas de relevo.

Quando 0 grau de alteração atinge 0 valor 100, é o domínio da ferralitização, no qual ocorre a paragênese caulinita-gibsita (MELFI e PEDRO, 1977).

Caso o grau de alteração seja inferior a 100, ocorrem dois domínios: o primeiro é o sialítico misto, com a formação de caulinita 
associada a argilominerais com grau incompleto de evolução. 0 segundo domínio é 0 da montmorilonita e corresponde à bissialitização verdadeira.

Em relação à terminologia, deve-se destacar que existe uma grande variedade de termos para o produto do intemperismo (TARDY, 1982). Assim, pode-se encontrar o termo zona pálida (OLLIER, 1969), cuja característica do produto do intemperismo é a perda de ferro e a apresentação de cores claras e com material rico em argila do tipo esmectita. Outros termos podem ser utilizados para os produtos do intemperismo, como por exemplo, saprolito grosseiro, saprolito fino (TRESCASTES, 1975; NAHON, 1991), arena plástica (LELONG, 1969) e litomarga com estrutura conservada (TARDY, 1993). Mas, os termos mais utilizados são isoalterita e aloterita (BOULANGÉ, 1984), Tabela 1.

Tabela 1 Organizações morfológicas ligadas a alteração.

\begin{tabular}{|l|l|l|l|}
\hline & $\begin{array}{l}\text { Estrutura } \\
\text { Litológica }\end{array}$ & $\begin{array}{l}\text { Textura } \\
\text { Petrográfica }\end{array}$ & $\begin{array}{l}\text { Volumes } \\
\text { Originais }\end{array}$ \\
\hline ISOALTERITA & $\begin{array}{l}\text { Conservada, } \\
\text { microsistema } \\
\text { de contato }\end{array}$ & Conservada & Conservados \\
\hline & $\begin{array}{l}\text { Conservada, } \\
\text { microsistema } \\
\text { fissural }\end{array}$ & $\begin{array}{l}\text { Não } \\
\text { Conservada }\end{array}$ & Conservados \\
\hline ALOTERITA & $\begin{array}{l}\text { Não Conservada, } \\
\text { microsistema } \\
\text { Plásmico Primário }\end{array}$ & $\begin{array}{l}\text { Não } \\
\text { Conservada }\end{array}$ & $\begin{array}{l}\text { Não } \\
\text { Conservados }\end{array}$ \\
\hline
\end{tabular}

Fonte: Boulangé (1984), Nahon (1991), Tardy (1993).

A isoalterita apresenta características morfológicas, químicas e mineralógicas herdadas da rocha com transformação isovolumétrica. Já na aloterita, as características morfológicas são determinadas pela pedoturbação, o mesmo ocorrendo com as características químicas e mineralógicas, nas quais ocorrem a destruição progressiva das feições de sustentação das estruturas primárias e as remobilizações geoquímicas.

0 saprolito apresenta diferenciação vertical, sendo litodependente. Sua característica básica é a transformação isovolumétrica (MILLOT, 1964; 1983; BOULET et al., 1977, NAHON, 1991). Este meio, o saprolito, é o responsável pelas transferências de soluções e reações geoquímicas que atuam no front de alteração, gerando argiloplasmas e cristaloplasmas, que expressam a natureza da rocha (NAHON, 1991).

A porção superior do saprolito foi chamada de saprolito fino (aloterita), por NAHON (1991). Ela apresenta alta porosidade e é pouco consolidada, constituindo-se pelo sítio de concentração de caulinita, óxidos e hidróxidos de ferro e alumínio (AMBROSI e NAHON, 1996). Mineralogicamente, o argiloplasma apresenta transformações para pedoplasma, que ocorre devido à lixiviação que envolve os horizontes que o recobrem (NAHON, 1991). A quantidade de argila aumenta, a despeito do esqueleto e, ainda que a caulinita não apresente reações intensas com a fase aquosa, apresenta reestruturação em microescala, sendo que em grande escala as estruturas e volumes permanecem intactos (NAHON, 1991).

O saprolito grosseiro (isoalterita) corresponde a uma unidade em que a estrutura original da rocha é preservada e apresenta volumes reliquiais tanto em nível micro, quanto macroscópico. Os pseudomorfos do material parental são gerados por cristaloplasmas, enquanto que o argiloplasma apresenta caulinita em formação (NAHON, 1991).

$\mathrm{Na}$ aloterita 0 processo dominante é pedoplasmação. A pedoplasmação é uma reorganização plásmica que resulta, necessariamente, de uma migração de matéria, com subtração, transporte em solução ou suspensão, além da acumulação e adição. Nela há separações plásmicas do tipo esquelssépica e vossépica. Já na isoalterita, ocorre a alteroplasmação (BOULET, 1978; TARDY, 1993), com as seguintes características:

- os mineriais secundários se desenvolvem in situ;

- as argilas, óxidos, oxiidróxidos e hidróxidos apresentam alteração pseudomorfa. A hidrólise nos minerais primários dáse por perda total dos elementos móveis (cátions alcalinos, alcalinos terrosos e sílica), ao mesmo tempo em que ocorre uma reprecipitação de elementos móveis e pouco móveis (ferro, alumínio e sílica);

- a neoformação dos minerais secundários realiza-se no interior dos cristais originais por nanotransferências de matéria. $\mathrm{Na}$ interface dos minerais ocorrem microtransferências intercristalinas de ferro e alumínio;

- na micromorfologia dominam as separações plásmicas do tipo assépica, argilassépica e silassépica.

Segundo TARDY (1993), a alteração alteroplásmica e a organização assépica caracterizam uma alteração intracristalina ou intramineral. Sua evolução geoquímica é condicionada pela natureza do mineral primário que se altera por meio de soluções com circulação lenta, sendo essencialmente mineralodependente.

A partir do contato da rocha com o saprolito, no chamado front de alteração, o perfil de intemperismo apresenta um aumento progressivo no grau de alteração (MABBUT, 1962) até a superfície (THOMAS, 1994). A velocidade de aprofundamento do front de alteração depende das características lito-estruturais e climáticas (BATTIAU-QUENEY, 1996).

0 avanço do front de alteração é dependente do nível d'água subterrâneo saturado (TARDY, 1993). Neste nível d'água 
subterrâneo saturado ocorre a contribuição de íons, cátions e ácidos orgânicos lixiviados dos horizontes pedoló-gicos (BÜDEL, 1982; THOMAS, 1994).

Para as áreas de Etchplanação Dinâmica, THOMAS e SUMMERFIELD (1986) estabeleceram sete tipos de perfis de alteração, cujas características dependem do balanço entre a alteração e a erosão com o decorrer do tempo. Posteriormente, THOMAS (1994) modificou as tipologias dos perfis, mantendo 0 princípio da relação acima enunciada. Estes sete perfis são:

1) PERFIL DE ABAIXAMENTO: ocorre quando há um balanço entre 0 aprofundamento do intemperismo e a denudação superficial. Dá-se em equilíbrio dinâmico entre a taxa de soerguimento da crosta com a denudação. $0 \mathrm{Fe}^{3+}$ precipita-se como goetita, a partir de nódulos hematíticos e acumula-se no horizonte B dos solos. Os veios de quartzo podem dar origem a stone-lines;

2) PERFIL DE APROFUNDAMENTO: depende do equilíbrio entre 0 abaixamento da superfície e 0 aprofunda-mento do intemperismo. Este perfil é possível somente em planaltos que estão protegidos por couraça ferruginosa que 0 protege da dissecação fluvial;

3) PERFIL DE COLAPSO: ocorre quando o solo ferralítico sofre hidromorfia e o $\mathrm{Al}^{3+}$, $\mathrm{Fe}^{2+}$ e $\mathrm{SiO}_{2}$ são lixiviados, transformandoos em podzóis;

4) PERFIL DE REDUÇÃO: quando ocorre 0 abaixamento gradual do front e as formações rochosas mais resistentes são preservadas em profundidade;

5) PERFIL DE TRUNCAMENTO: distingue-se do perfil de redução porque neste tipo é intensa a erosão superficial, que remove tanto os horizontes superficiais quanto 0 saprolito fino. Este tipo de perfil está relacionado às variações climáticas e à dissecação fluvial;

6) PERFIL COMPLEXO: pode ocorrer se a taxa de sedimentação supera a de erosão. Típico de área que está sofrendo subsidência tectônica;

7) PERFIL RENOVADO: ocorre por meio da ação de muitos processos que envolvem a dissecação da paisagem, mas conservando 0 saprolito.

No trabalho Long-Term Landform Development Key: Themes and Research Problems, THOMAS e SUMMERFIELD (1986) caracterizaram um outro tipo de perfil, o perfil de diferenciação, que ocorre sob relevo estável, onde 0 nível do lençol freático é constante no tempo, sendo um tipo de perfil que envolve a cobertura pedológica. No entanto, THOMAS (1994:85) não 0 considerou como típico, uma vez que, segundo 0 autor, a pedogênese é um tópico que deve ser tratado em separado, pois a diferenciação dos horizontes não é necessariamente vertical. THOMAS (op.cit.), então, incorpora notadamente, a noção de sistemas de transformação (BOULET et al., 1992). Tal fato fica evidente quando 0 autor trata a questão da transformação de latossolos em podzóis, sendo esta noção também utilizada como elemento comprovador do abaixamento das paisagens por ação geoquímica (THOMAS, 1993:48).

A formação e a evolução do solo ocorre sob 0 efeito de fatores bioclimáticos que intervêm na alterita, provocando redistribuição, reestruturação e organização dos horizontes. Os horizontes quando estão em clímax sucedem-se verticalmente numa série que corresponde a uma ou diversas seqüências de organizações elementares, derivando umas das outras, com uma orientação vertical (BOULET et al., 1984).

Para CHAUVEL e LUCAS (1992), a natureza da transformação do saprolito em solo depende do balanço de três processos:

- alteração dos minerais;

- transporte em solução;

- autigênese de minerais secundários.

Estes processos resultam de um novo equilíbrio termodinâmico, controlado pelas condições físico-químicas que existem no perfil do solo em relação à rocha. Tais processos atuam primeiro na base do perfil, conduzindo à formação de materiais residuais $\mathrm{e}$ neoformados, assim como a uma nova estrutura (CHAUVEL e LUCAS, 1992).

Quando o solo se aprofunda, novas condições físicoquímicas são impostas ao perfil e, conseqüentemente, os processos de alteração, transporte e autigênese interagem com 0 solo inicial originando um outro, com composição e estrutura diferentes. Esta diferenciação produz os horizontes, que refletem a variação espacial do ambiente pedológico (NAHON, 1991; Chauvel e Lucas, 1992).

0 desenvolvimento do solo e, conseqüentemente, de seus horizontes, ocorre em meio não saturado (TARDY, 1993) por meio dos fronts pedogenéticos (BOULET et al., 1993) que avançam em diferentes graus sobre 0 saprolito, bem como em equilíbrio dinâmico (CHAUVEL e LUCAS, 1992:141).

Os fronts pedogenéticos são os seguintes (CHAUVEL e LUCAS, 1992; NAHON, 1991):

1) FRONT DE DEGRADAÇÃO: ocorre no horizonte superficial e é o responsável pela concentração de minerais residuais, como 0 quartzo. 0 mecanismo que atua na formação deste front é o biogeoquímico, por meio da ação dos ácidos orgânicos; 
2) FRONT DE MICROAGREGAÇÃO: corresponde ao limite inferior do horizonte Bw. Esta estrutura é produzida por processos inorgânicos em um ambiente ácido caulinítico e bem drenado;

3) FRONT DE PEDOPLASMAÇÃO: corresponde à transformação do saprolito fino em horizonte pedológico, por meio da reorganização estrutural e mineralógica.

Com 0 avanço dos fronts pedogenéticos sobre 0 saprolito e a conseqüente transformação deste em solo, o material original sofre uma perda de volume, cerca de $70 \%$, segundo CHAUVEL et al. (1983) e MILLOT (1980, 1983). Esta redução, de acorde com NAHON (1987), ocorre devido ao colapso da estrutura ferro-argila e à lixiviação dos oxiidróxidos de ferro e alumínio. Permanece, assim, apenas 0 esqueleto residual, representado pelo quartzo no horizonte superficial, que conduz à etchplanação.

Quando 0 ambiente apresenta-se em equilíbrio dinâmico (BOULET et al., 1983,1984) as evoluções climáticas e tectô-nicas são insuficientes para criar condições de desequilíbrio. Desta forma, as estruturas pedológicas expressam lito-dependência com acumulação relativa ou absoluta e subtração de material.

A acumulação relativa é essencialmente vertical, in situ, e dáse por reconstrução dos elementos químicos móveis no intemperismo mineral. A acumulação absoluta ocorre na parte superior do horizonte, durante 0 abaixamento da sequeência pedológica na paisagem. Já a subtração de material ocorre tanto vertical quanto lateralmente.

Em cada front os elementos podem ser móveis na forma de solução ou como solutos finos. Os componentes solúveis liberados pelo intemperismo podem precipitar-se imediatamente como novos minerais ou ser transportados para outro horizonte. Quando as condições físico-químicas são mais favoráveis para a precipitação ou lixiviação em todo o perfil, as partículas sólidas são liberadas pela desestabilização da fábrica do solo e pelo avanço dos fronts, sendo transportadas por iluviação mecânica (CHAUVEL e LUCAS, 1992; NAHON, 1991; TARDY, 1993).

Porém, quando a cobertura pedológica entra em desequilíbrio, seja por mudança climática, tectônica ou hidrodinâmica, forma-se um sistema de transformação (BOULET et al., 1982), no qual as estruturas tornam-se instáveis e transformamse para dar origem a novas estruturas, estabelecendo 0 equilíbrio com as novas condições pedobioclimáticas. As novas organizações se sucedem de maneira ordenada, sendo discordantes em relação àquelas da cobertura inicial e se propagam lateralmente às custas destas.

É o caso verificado por LUCAS (1989) na região norte de Manaus (AM), com a transformação de latossolo em podzol.
Geomorfologicamente, a região ao norte de Manaus apresenta planaltos aplainados com latossolo, sendo que a mesma grada para uma superfície intermediária, que possui vertentes íngremes, onde se localizam as cabeceiras de drenagem. No planalto, o latossolo apresenta uma diferenciação vertical, que favorece a precipitação nos horizontes subjacentes de oxiidróxidos de ferro e alumínio na forma de nódulos, conduzindo a uma diferenciação em fronts de microagregação e nodular. Quando o latossolo se aproxima da superfície intermediária, a drenagem interna passa de vertical para lateral, favorecendo a migração da matéria orgânica na forma de MOR, que promove a destruição da caulinita e dos oxiidróxidos de ferro e alumínio, que, por sua vez, reprecipitam-se em diferentes profundidades em um horizonte $\mathrm{Bh}$ ou Bfe, com acumulação relativa de quartzo e formação de podzol. Na medida em que o front de podzolização avança em direção ao planalto, intensifica-se a erosão nas cabeceiras de drenagem. As vertentes que inicialmente eram curtas e íngremes, com 0 avanço do front de transformação, passam a ser mais extensas, suaves e apresentam diminuição da altitude relativa.

Esta situação é interpretada (LUCAS, 1989; CHAUVEL e LUCAS, 1992) como indicativa de um abaixamento da paisagem por redução do saprolito em profundidade e por transformação do latossolo em podzol, graças à hidromorfia que se generaliza no interior do perfil, à medida em que a superfície é reduzida por colapso da estrutura do solo e pela liberação do alumínio.

Estudando uma barra pré-litorânea na Guiana Francesa, em um sistema de solo ferralítico-podzol, sobre sedimento marinho areno-argiloso, BOULET, (1988); BOULET et al. (1983;1984) encontraram os seguintes estágios de evolução:

- Estágio I: corresponde a uma cobertura inicial constituída por um solo ferralítico areno-argiloso, de cor bruno vivo e amarelo-avermelhado, permeável e de variação vertical progressiva na textura;

- Estágio II: nos lugares com drenagem externa minima, desenvolvem-se horizontes fortemente empobrecidos em argila, com variação rápida de textura na base;

- Estágio III: 0 empobrecimento progrediu lateral-mente. Nos lugares onde havia iniciado o processo instalou-se, ao nível da variação textural rápida, uma frente de transformação dos horizontes empobrecidos cada vez mais arenosa. Nele, quando o teor de argila é inferior a dois por cento (2\%), aparece areia branca e acumulação de ferro ao nível da frente de transformação: é o início da podzolização (Estágio IV). Esta progride lateralmente e acaba por invadir toda a barra, acompanhada de um 
aplainamento geoquímico (BOULET, 1988).

Para que ocorra a ectchplanação dinâmica é necessário um regime cratônico passivo que se desenvolva em uma plataforma ou crosta continental estabilizada em um núcleo de idade Arqueana (FAIRBRIDGE e FINKL, 1980), palco de flutuações climáticas, isostática, glacio-eustática, glacial e de reativação de lineamentos. As margens cratônicas classi-ficadas como passivas são aquelas que se apresentam estabilizadas nos últimos 100 milhões de anos (OLLIER, 1985).

Para FAIRBRIDGE e FINKL (1980), as margens de regime cratônico passivo caracterizam-se pela alternância de fases biostáticas, envolvendo 109 anos, alternada por fase resistática de 105 a 107 anos. A fase biostática é uma fase estável, na qual 0 intemperismo químico promove 0 abaixamento do relevo, criando a etchplanação, enquanto que a resistática é uma fase instável, que gera estresse na paisagem, criando a pediplanação. Em suma, as fases de etchplanação e pediplanação constituem 0 ciclo de evolução poligênica do modelado, fazendo parte da dinâmica das margens cratônicas passivas.

Segundo THOMAS (1994), o uso da noção de dinâmica do sistema de intemperismo e a formação do perfil de intemperismo em margens continentais passivas em regiões tropicais permitem 0 estabelecimento das relações entre as taxas de aprofundamento do intemperismo, a dinâmica dos processos erosivos e os processos de aplainamento do relevo. THOMAS (1994a) identificou cinco mecanismos de abaixamento do relevo nas regiões tropicais, que estão associados a processos físicos e químicos. São eles:

- 0 acúmulo de $\mathrm{Fe}, \mathrm{Ni}$ e outros minerais pesados no perfil de intemperismo;

- 0 acúmulo de seixos e cascalhos nos interflúvios e na porção superior das vertentes;

- abaixamento por etchin do fundo dos vales, com o canal transportando solutos e finos;

- a ferrólise das argilas em ambiente hidromórfico, com a formação das "areias brancas";

- a dissolução das rochas e a formação de depressões cársticas em terrenos cristalinos.

Ainda segundo THOMAS (1994a), alguns estudos detalhados sobre 0 intemperismo em zonas marginais de alguns continentes nas regiões tropicais permitiram construir algumas interpretações sobre os mantos de intemperismo e seu significado para 0 desenvolvimento do relevo. Sumariamente, as interpretações são as seguintes:

a) Os perfis de intemperismo excedem 50 metros de espessura e estão associados a colinas mamelonares.
Característica de relevo marcante na costa brasileira, na costa da República dos Cameroon e no oeste de Borneu;

b) 0 aprofundamento do intemperismo ocorre em relevo muito dissecado, como é o caso da Serra do Mar no Brasil, em Hong Kong e em Serra Leoa (África);

c) Os saprolitos raramente estão associados a lateritas desenvolvidas in situ, mas apresentam stones lines;

d) Nas antigas superfícies de aplainamento em que predomina 0 manto fersialitico, a taxa de aprofundamento do intemperismo é lenta, muito embora apresente uma quantidade significativa de matacões em seu interior. Ocorrem no sudeste do Brasil, na Austrália, em Hong Kong e na Malásia;

e) Onde 0 perfil de intemperismo caracteriza-se por ser ferralitico, os horizontes apresentam-se bauxitizados e semelhantes aos processos atuais;

f) Os movimentos de massa são generalizados e sugerem uma relação ativa entre 0 intemperismo e a morfogênese.

Em Serra Leoa, na África, procurando estabelecer as relações entre o regolito e o desenvolvimento do relevo, TEEUW et al. (1994) observaram que 0 estilo de paisagem desenvolvido era similar ao regime cratônico proposto por FAIRBRIDGE e FINKL (1980), com uma fase de prolongado abaixamento da paisagem, dominado por eluviação química e baixa transferência energética de finos em biostasia, contrastado com períodos resistáticos, quando predominava rápida erosão superficial $\mathrm{e}$, conseqüentemente, a diferenciação do relevo. Outra característica importante é que durante os processos de etching, os autores observaram uma participação importante dos canais fluviais na exportação de sedimentos finos e a conseqüente acumulação de material grosseiro nos interflúvios.

Desta forma, 0 uso do perfil de intemperismo para a análise geomorfológica é possível somente em áreas cratônicas estáveis (FAIRBRIDGE e FINKL, 1980), uma vez que a estabilidade é necessária para que ocorra 0 aprofundamento do front de alteração com as conseqüentes transformações mineralógicas e estruturais no interior do perfil (THOMAS, 1994; TWIDALE, 1983; KROONENBERG e MELTZ, 1983; OLLIER, 1985; BATTIAUQUENEY, 1996), propiciando, com isto, o processo de etchplanação.

\section{Hipótese sobre a formação da Etchplanação dinâmica e episódica nas margens cratônicas passivas em região tropical quente e úmida}

A dinâmica da Etchplanação nos trópicos úmidos está integrada à dinâmica da drenagem, que se constitui em nível de 
base para 0 aprofundamento do front de alteração e para a remoção de solutos e finos (THOMAS, 1994).

As concepções sobre a evolução do relevo nas regiões tropicais quentes e úmidas fundamentaram-se na Teoria da Pediplanação (KING, 1953) na qual as variações estrati-gráficas, 0 posicionamento das cascalheiras e das linhas de pedra na topografia da vertente, associadas às flutuações glácio-eustáticas, serviu como indicadores dos processos denudacionais, permitindo a correlação entre os materiais e as formas e das formas com as fases de desequilíbrio da paisagem.

No entanto, a teoria da Etchplanação vem recentemente questionando o caráter cíclico do relevo, argumentando que a teoria da pediplanação considera apenas os processos climáticos agressivos, menosprezando 0 papel do intem-perismo no condicionamento e na dinâmica das formas de relevo (SUMMERFIELD, 1991; THOMAS, 1994; TWIDALE e RAMANI, 1994).

Para os autores acima, a etchplanação sofre o controle do clima e da tectônica em um determinado tempo, uma vez que os mesmos comandam o aprofundamento do front de intemperismo, com a concomitante perda gradual de finos e solutos nos horizontes superficiais.

No entanto, deve-se destacar que na etchplanação o papel da tectônica é muito generalizante e, principalmente, não se discute o papel do nível de base e da dinâmica fluvial na evolução das formas de relevo.

Nas regiões tropicais quentes e úmidas, a erosão fluvial é dependente da posição gemorfológica do canal, como Kinick aponta points, rápidos afunilamentos, meandramentos e variações litológicas no canal, que podem estar associados à tectônica e às características climáticas. Estas características do canal-sistema fluvial podem determinar o tempo de armazenamento dos sedimentos fluviais, que também devem ser incorporados na etchplanação. Outra propriedade das características geomorfológicas do canal fluvial, como as acima relatadas, é condicionar a quantidade do fluxo de água e sua velocidade, bem como 0 estoque de águas do lençol suspenso das encostas e do aqüífero, que, por sua vez, exercem controle no aprofundamento do front de alteração e no conseqüente abaixamento-planação do relevo, sob uma ótica regional e de domínio do quaternário (VITTE, 1998; 2001).

Quanto à tectônica, deve-se destacar a recente, ou seja, a neotectônica, (JAIN, 1980; HOWARD, 1967), uma vez que é mais um mecanismo que intensifica a ação do sistema fluvial e subsuperficial das encostas (LEOPOLD et al., 1964; SCHUMM,
1977). Assim, sob condições de subsidência, o sistema fluvial tem condições de formar amplas planícies aluviais com um tempo de recorrência maior para que ocorra a regressão das cabeceiras de drenagem (VELDKAMP e DYKE, 1994), enquanto que em condições de soerguimento, a regressão das cabeceiras é mais intensa, promovendo, inclusive, maior remobilização do regolito.

Outra questão que a etchplanação se depara refere-se ao papel das mudanças climáticas. Muito embora THOMAS (1994) tenha procurado equacionar 0 papel dos paleoclimas na constituição das formas de relevo, é inegável que além da redistribuição dos materiais, a fase resistática (pediplano) do relevo viabiliza a constituição e a complexização de novas formas, seja pela exposição do front de alteração e formação de inselbergs, ou mesmo pela produção de novos inputs de matéria e energia nas formas, durante a fase biostática (etchplains). É o caso dos perfis complexos ou polipedomórficos, nos quais as tipologias dos materiais, condicio-nadas pelo grau e tipo de alteração, quando da remobilização sob novas condições ambientais, permitem não somente uma mudança nos padrões hidrológicos da vertente, com condições hidráulicas favoráveis à formação de níveis suspensos de saturação, mas também novas condições de diferenciações na alteração por meio da redistribuição de minerais primários e secundários.

\section{Considerações finais}

Devido à força paradigmática da pediplanação, o papel do intemperismo químico/pedogênese nas regiões tropicais quentes $\mathrm{e}$ úmidas e do aplainamento do relevo ficou menos-prezado na análise geomorfológica. A Teoria da Etchplanação procura abordar os processos de aplainamento pela ação geoquímica no relevo. No entanto, deve-se destacar que na análise geomorfológica, a teoria da Etchplanação deve ser avaliada em um quadro de referência maior, ou seja, pela noção de geomorfologia climatogenética e pela evolução do relevo inserida na noção de poligenia, na qual o relevo é o produto de um ciclo de etchplanação-pediplanação.

No entanto, a operacionalização da etchplanação encon-tra alguns problemas, tais como a ausência de uma base escalar fixa que poderia ser regional: as bacias de drenagem seriam bastante adequadas para tal fim, mesmo porque a geomorfologia do canal e a dinâmica do sistema fluvial, como um todo, também participam ativamente do processo de aplainamento geoquímico do relevo, condicionando o tempo de estocagem e a velocidade do fluxo da água no aqüífero.

Outro ponto importante que foi muito generalizado na etchplanação e pouco detalhado é relativo aos solos, e, neste 
sentido, a noção de cobertura pedológica e de sistemas de transformação, pode perfeitamente auxiliar as análises geomor- fológicas, pois permite uma maior integração entre o relevo e o solo no quadro teórico dos etchplains. 
VITTE, A. C. (2005). Dynamic and episodic Etchplanation in warm and wet tropical regions. Revista do Departamento de Geografia, n. 16, p. 105118.

Abstract: This paper examines the etchplanation theory, a recent approach in geomorphology. This theory is suitable to study landforms in wet and warm tropical regions, since it considers chemical weathering and transformation of systems by pedological processes and levelling landforms. The originality of Etchplanation theory relies on the consideration of geochemical and pedogenetics processes as very important mechanisms, which are related to morphogenesis and levelling landform. On discusses the Etchplanation theory genesis, the Etchplanation in tropical regions, the chemical weathering as a basic mechanism for levelling landforms and the proposition of work considering Etchplanation.

Key words: Wet and warm tropical regions; Etchplanation; Chemical Weathering; Pedological covering; Drainage basin.

Recebido em 7 de setembro de 2005, aceito em 2 de outubro de 2005.

\section{Referências}

ABREU, A.A. de. (1982) Análise geomorfológica: reflexão e aplicação - uma contribuição ao conhecimento das formas de relevo do planalto de Diamantina-MG. SP, FFLCH-USP, Tese de Livre-Docência. 293p.

AMBROSI, J.P.; NAHON, D. (1996) Petrological and geochimical differentiation of lateritic ion crust profiles. Chem. Geol., 57. p. 371-393.

BATTIAU-QUENEY, Y. (1996) Contraints from deep-crustal structure on long-ternm landform development of the British Isles and Eastern United States. Gemorphology, 2. p. 53-70.

BOULET, R. (1974) Toposéquences et sols tropicaux en Haute Volte: équilibres dynamiques et bioclimats. Strasbourg, these docteur sciences naturelles. 330p.

; et al. (1977) Géochimie de la surface et formes du relief. I desequilibres pedobioclimatique dans le couvertures pedologiques de L'Afrique tropicale de L'Ouest e son role dans l'aplamissenant des reliefs. Sc.Glob. Bull. Strasbourg, 30(4). p. 235-43.

(1978) Existence de systemes fort differenciation laterale en milieu ferralitique: un nouvel exemple de couverture pedologique en desequilibres. Sc. du Soil., 2. p. 75-82.

(1983/1984) Les systemes de transformation en pedologie. Cah.ORSTOM, Ser. Pedologie. p. 167-179.

; et al. (1984) Analyse structurale de la couverture pedologique et experimentation agronomique en Guyane Française. Cah. ORSTOM, Ser. Pedologie. XXI, (1). p. 21-31.

(1988) Análise estrutural da cobertura pedológica e cartografia de solos. XXI Congr. Bras. Solo., Campinas. p.7990.

BOULANGE, B. (1984) Les formations bauxitiques latéritiques de
Côte d'Ivoire. Les facies, leur transformations, leur distribuitions et L'évolution du modelé. Trav. Et Doc. ORSTOM, Paris. 367p.

BORNHARDT, W. (1900) Zur geologie und oberflachengestaltung Deustsch-Ostafrikas. Berlin.

BERRY. L. e RUXTON, B. (1957) The evolution of Hong-Kong harbeur basin. Zeits. Geomorf. 4. p. 97-115.

BREMER, H. (1971) Flusse, flächen und stufenbildung in den feuchten tropen. Wurzburger Geogr Arb., 35.

(1977) Ayers rock ein beispiel fur klimagenestische morphologie. Zeits Geomorph., 9. p. 249-284.

(1981) Reliefformen und reliefbildende prozesse in Sri Lanka. Relief, Boden, Paläoklima, 1. p. 1-184.

(1992) Relief and soil in the tropics - a data base. Zef. Geomorph (suppl), 91. p. 1-10.

(1993) Etchplanation, review and comments on Büdel's model. Zets. Geomorph (supp), 92. p. 161-171.

BUDEL, J. Das system der klimatischen morphologie. Der Geographentag Müchen. p. 65-100, 1948, Landshute, 1950.

(1954) Klemia morphologische arbeiten in athiopten in fruhjahr. Erkunde, 8(2). p. 139-156.

(1957) Die "Doppelten Einebnungsflachen" in den fenchten troppen. Zeif. Geomorph., 1(2). p. 201-228.

(1963) Klema genetische geomorphologie. Geograph. Rundschau. 15(7). p. 269-285.

(1969) Das system der klemia genetschen geomorphologie. Erkunde, XXIII (1/4). p. 165-183.

(1977) Klima - Geomorphologie. Berlim-Stuttgart. 304p.

(1980) Climatic and climatogenetic (climatomorhic) geomorphology. Z. Geomorph., (suppl), 36. p. 1-8.

(1982) Climatic geomorphology. Princepton, Princeton Univ. Press. 443p. 
CHAUVEL, A. e LUCAS, Y. (1992) Soil formation in tropically weathered terrains. In: GOVETT, C.J.S. (ed) Handbook if Exploration Geochemistry. NY, Elseveier. p. 57-77.

CHORLEY, R.J., SCHUMM, S.A. e SUDGEN, D.E.: (1984) Geomorphology. NY, John Wiley \& Sons. 605p.

DAVIS, W. M. (1899) The Geographical Cycle. Geogr. Journ. 14. p. 481-504.

DOUGLAS, I. (1969) The efficiency of humid tropical dlenudation system. Transc. Inst. Brist. Geogr. 46. p.1-16.

FAIRBRIDGE, R.W. e FINKL, C.W. (1980): Anatomic erosional unconformities and peneplains. Journal of Geol., 88. p.69-89,

FANIRAN, A. e JEJE, L.K. (1983) Humid tropical geomorphology. New York, Longmam. 414p.

HOWARD, A.D. Drainage analysis in geology interpretation: a summation. Bull. Am.Ass. of Petrolium Geologist., vol. 51. p. 2245-2259.

JAIN, V.E. (1980) Geotectônica global. Moscou, Ed. Mir, 350p.

JESSEN, O. (1936) Reisen und forschungen in Angola. Berlin. 397p.

KHUN, T. (1986) A estrutura das revoluções científicas. São Paulo, Perspectiva. 4 ed. 257p.

KING, L.C. (1953) Canons of Landscape evolution. Bull. Geol.Soc. Am., 64. p. 721-752.

KROONENBERG, S.B. e MELITZ, J.P. (1983) Summit levels bedrock control and the etchplain concept in the basement of Suriname. Geol. Mijn, 62. p. 389-399.

LEOPOLD, L. B. et al. (1964) Fluvial processes in geomorphology. San Francisco, Freeman \& Company. 203p.

LELONG, F. (1969) Nature et genése des produits d'alteration des roches cristallines sous climat tropical humid (Guyane Française). Mém Sc. Terre, Nancy, 14. 188p.

LUCAS, Y. (1989) Systemes pedologiques en Amazonie Brasilienne. Equilibres, desequilibres et transformations. These Docteur, Univ. Poitiers. 153p.

MABBUTT, J. A. (1962) A stripped landsurface in western Australia. Transc. Inst. Brit. Geogr., 29. p. 101-114.

MELFI, J. A. e PEDRO. G (1977). Estudo geoquímico dos solos e formações superficiais do Brasil. Parte 1 - tipos de evolução pedogeoquímica. Revista Bras. Geociências, (4), p. 271-286.

MILLOT, G. (1964) Géologie des argiles. Masson, Paris. 494p. (1980) Les grands aplanaissements des soles continentaux dans les pays subtropicaux, tropicaux et desertiques. Mém. ORSTOM, Soc. Geol. France, 10. p. 295-305.

(1983) Planation of continents by intertropical weathering and pedogenetic processes. In: MELFI, A.J. e CARVALHO, A. de. (orgs.) Laterisation Processes. Proceedings II International Seminar on Laterisation Processes. São Paulo, Brasil. p. 5363.

NAHON, D. B. (1987) Evolution of iron crusts in tropical landscape. In: COLEMAN, S.M. e DETHIER, D.P. (eds) Rates of Chemical Weathering of Rocks and Minerals. Academic Press Inc. p. 169-191.

(1991) Introduction to the petrology of soils and chemical weathering. NY, John Wiley \& Sons. 313p.

NOVIKOROFF, A. (1943) Introduction to paleopedology. Am. Journ. Sc., 24. p. 194-200.

OLLIER, C. (1969) Some features of granite weathering in Australia. Zeits Geomorph., vol. 3. p. 285-304.

(1975) Weathering. NY, Longmann. 304p.

(1985) Morphotectonics of passive continental margins: introduction. Zeits. Geomorph.,(sup), 54. p.1-9.

PASSARGE, S. (1895) Adamuana. Berlin. (1904a). Die kalahari, 2 vols, Berlin.

(1904b) Über rumpflachen und inselberge. Z. Dt. Geol. Ges. 56. p.193-207.

(1904c) Die inselberglandschaft im tropischen Afrika. Naturwiss Wochenschr, 3. p. 657-665.

(1924) Das problem der skulpur-inselberglandschaften. Paterm Geogr Mitt., 70. p. 117-120.

(1929) Das problem der inselberglandschaften. $Z$. Geomorph. 4. p.109-122.

PELTIER, L.C. (1950) The geographical cycle in periglacial regions as it is related to climatic geomorphology. Ann. Ass. Am. Geogr., 40. p. 214-236.

PEDRO, G. (1966) Essai sur la caracterisation géochimique des différents processus mineraux résultant de l'alteration des roches superficialles cycles aluminisiliciques. CR. Acad. SC. Paris, 261. p. 1828-1831.

(1968) Distribution des principaux types d'alterations chimique de la surface du globe. Presentation de une esquisse géographique. Géol. Phy et Géomph. Dynamique. 10. p. 457470.

; et al. (1975) Recherches sur la constitution et la génese des terras roxas estruturadas du Brésil. Introduction a une étude de la pedologie ferralitique. Ann. Agron. (27). p. 263-294.

; MELFI, J.A. (1983) The superficial alterations in tropical regions and laterisation phenomena. In: MELFI, J. A. e CARVALHO, A. (orgs) Laterisation Processes. Proceedings II 
International Seminar on Laterisation Processes. São Paulo, Brasil. p. 4-12.

SCHUMM, S.A. (1977) The fluvial system. NY, John Wiley \& Sons. 230p.

STODDART, D.R. (1969) Climatic geomorphology. Progress in Geography, Londres, Edward Arnold. p. 160-222.

STRAKHOV, N.M. (1963) Principles of lithogenesis. Edinbourgh, Oliver \& Boyd. 230p.

SUMMERFIELD, M.A. (1991). Global geomorphology. NY, John Wiley \& Sons. 245p.

TARDY, Y. (1969) Géochimie des altérations. Étude des arenses et des eaux de quelques massifs cristallines d'Europe et d'Afrique. Mém. Sev. Carte Géol. Alsace-Lorraine, 31.

(1982) Le cycle de l'eau. Climats, paleoclimats et géochimie globale. Masson, Paris. 338p.

(1993) Pétrologie des laterites et des sols tropicaux. Masson, Paris. 416p.

TEEUW, R.M.; THOMAS, M.F.; THORP, M.B. (1994) Regolith and landscape developmment in the Koidu Bassin of Sierra Leone. In: ROBINSON, D.A e WILLIAMS, R.B.G. (eds.) Rock Weathering and Landform Evolution. NY, John Wiley \& Sons. p. 303-320.

THOMAS, M. (1974) Tropical geomorphology. A study of weathering on landform development in warm climate. NY, John Wiley \& Sons. 313p.

; SUMMERFIELD, M.A. (1986) Long-term landform development: key themes on research problems. In: GARDNER, V. (org.) International Geomorphology, part II, NY, John Wiley \& Sons. p. 935-956.

(1989) The role of etch professes in landform development. I. Etching concepts ond their applications. Zeits. Geomorph., jun, 33(2). p. 129-142.

(1989a) The role of etch processes in landform development. II etching and the formation of relief. Zeits. Geomorph, 33(3). p. 257-274.
(1994) Geomorphology in tropics: a study of weathering and denudation in low latitudes. NY, John Wiley \& Sons. 443p.

(1994a) Ages and geomorphic relationships of saprolite mantles. In: ROBINSON, D.A e WILLIAMS, R.B.G. (eds.) Rock Weathering and Landform Evolution. NY, John Wiley \& Sons. p. 287-302.

TRECASTRES, J.J. (1975) L'evolution géochimique superene des roches ultrabasiques en zone tropicale. Formation des gesementes nickélferes de nouevelle-caledonie. Mém. ORSTOM, Paris, 78. 259p.

TRICART, J. (1972) The landforms of the umid tropics, forests and savannas. Londres, Longman.

TWIDALE, C.R. (1983) Pediments, peneplains and ultiplains. Rev. Geomorf. Dynamique.,32. p.1-35. ; LAGET, Y. (1993) Climatic geomorphology: a critique. Progress Phys. Geogr., 18. p. 319-334.

; VIDAL-ROMANI, J.R. (1994) On the multistage development of etch forms. Geomorph., 11. p. 107-124.

VELDKAMP, A.; VAN DYKE, J.J. (1994) Modelling of potential effects of long term fluvial dynamics on possible geological storage facilites of nuclear waste in the Netherlands. Geol. Mijn., 72. p. 237-249.

VITTE, A.C. (1998) Etchplanação em Juquiá (SP): relações entre 0 intemperismo químico $\mathrm{e}$ as mudanças climáticas no desenvolvimento das formas de relevo em margem cratônica passiva. Tese de Doutoramento, FFLCH, Universidade de São Paulo, USP, São Paulo.

(2001) Considerações sobre a teoria da etchplanação e sua aplicação no estudo das formas de relevo nas regiões tropicais úmidas. Terra Livre, 16, parte I. p. 11-24.

WAYLAND, E.J. (1933) Peneplains and some other erosional plataforms. Ann. Rept. Bull. Protectorate of Uganda Geol Surv., note 1. p. 77-79.

WIRTHMANN, A. (1999) Geomorphology of the tropics. Berlin, Springer. 314p. 